\title{
Inferior Alveolar Nerve Paresthesia After Overfilling of Endodontic Sealer Into the Mandibular Canal
}

\author{
Maríbel González-Martín, PhD, DDS, Daniel Torres-Lagares, PhD, DDS, José Luis Gutierrez- \\ Pérez, PhD, MD, DDS, and Juan José Segura-Egea, PhD, MD, DDS
}

\begin{abstract}
The present study describes a case of endodontic sealer (AH Plus) penetration within and along the mandibular canal from the periapical zone of a lower second molar after endodontic treatment. The clinical manifestations comprised anesthesia of the left side of the lower lip, paresthesia and anesthesia of the gums in the third quadrant, and paresthesia and anesthesia of the left mental nerve, appearing immediately after endodontic treatment. The paresthesia and anesthesia of the lip and gums were seen to decrease, but the mental nerve paresthesia and anesthesia persisted after 3.5 years. This case illustrates the need to expend great care with all endodontic techniques when performing nonsurgical root canal therapy, especially when the root apices are in close proximity to vital anatomic structures such as the inferior alveolar canal. ( $J$ Endod 2010; $\square: 1-3)$
\end{abstract}

\section{Key Words}

Endodontic complications, paresthesias of the inferior dental nerve

Address requests for reprints to Dr Juan José Segura-Egea, Professor of Endodontics, Department of Stomatology, Schoo of Dentistry, University of Seville, C/Avicena s/n, 41009 Seville, Spain. E-mail address: seguraij@us.es.

0099-2399/\$0 - see front matter

Copyright (c) 2010 American Association of Endodontists. doi:10.1016/j.joen.2010.03.008
The elimination of all diseased pulp and dentin, adequate cleaning and shaping of the root canal system, and its 3-dimensional obturation and sealing constitute the basic principles of endodontic treatment. Ideally, the filling material should be limited to the root canal without extending to periapical tissues or other neighboring structures. However, overinstrumentation of the root canal with hand or mechanically driven files can perforate the mandibular canal, allowing the extrusion of sealers, dressing agents, and irrigation solutions and the passage of microorganisms into the canal during endodontic treatment (1).

Totally biocompatible materials are not available. Consequently, their spread beyond the apical foramen can give rise to clinical manifestations in relation to the toxicity of the product, although minor material extrusions are generally welltolerated by the periradicular tissues (2). Sealers and filling materials differ chemically and include, among others, AH Plus, AH 26, Hydron, Diaket, Iodoform, Calasept, Endoseal, and chloropercha. Some of them can cause serious neurotoxic complications when extruded into the mandibular canal (3-5). Undesirable complications such as anesthesia, paresthesia, hypoesthesia, hyperesthesia, and dysesthesia can follow the extrusion of an endodontic sealer into the mandibular canal (6-12).

The first symptom of the overfilling into the mandibular canal is sudden pain expressed by the patient during obturation of the root canal, which persists after the disappearance of the local anesthetic effects (13). The pain can be accompanied by local inflammatory signs, with the endodontically treated tooth being painful to percussion, painful on palpation of the vestibular alveolar process, or a combination of signs of mechanical lesions and inferior dental nerve inflammation with pain or numbness of the lower lip or otalgia (6). Some patients experience the persistence of the local anesthesia $(12,14)$.

The present study describes a case in which endodontic sealer AH Plus spread to the mandibular canal, causing paresthesia and anesthesia in the area of innervation of the inferior alveolar nerve.

\section{Case Report}

A 32-year-old woman was referred for root canal treatment in the left second molar tooth because of an apical periodontitis subsequent to caries. The initial diagnosis for the tooth was acute apical abscess (15). She neither smoked nor consumed alcohol and had no personal or family disease antecedents of interest. Two years before, her first mandibular left molar had been extracted, and an endosseous root-formed implant had been placed, supporting a metal-ceramic crown. After adequate anesthesia and isolation with rubber dam, an endodontic access cavity was established. Three canal orifices were defined. After apical patency, the root length was estimated by using an apex detector (AFA Apex Finder; Analytic Technology, Orange County, CA) and then confirmed with a periapical radiograph. The root canal treatment was carried out by involving canal shaping with hand files by using the step-back technique and saline irrigation. After cleaning and shaping, the canal was dried and obturated with AH 26 (Dentsply DeTrey GmbH, Konstanz, Germany) and gutta-percha by using the lateral condensation technique. A small quantity of sealer was introduced into the root canal by using a manual instrument, then the main cone was placed and covered with a minimal quantity of sealer, and cold condensation was performed. Moreover, each additional cone was covered with a minimal quantity of sealer. There were no complications during treatment. 


\section{Case Report/Clinical Techniques}

Just after endodontic treatment, the postoperative periapical radiograph revealed the presence of radiopaque canal sealer in the mandibular canal (Fig. 1). Nevertheless, the patient was still under the effect of the anesthetic, and she reported no pain or other discomfort after the root canal treatment.

The day after, no swelling, redness, or other signs of inflammation were observed on intraoral exploration. However, the patient reported numbness on the left side of the lower lip and a tingling sensation in the vestibular gingival and in the lower left premolar and anterior teeth. Extraoral examination likewise failed to identify swelling, alterations in skin color, or adenopathies. The anesthetized zone was delimited by tactile exploration, and anesthesia in the region served by the left inferior alveolar and mental nerve was observed. The buccal gingival tissues over the left mandibular molar and premolar teeth felt no sensation; there was no sensation to thermal or mechanical stimuli in either the left lower lip or buccal gingivae. The lingual gingival tissues responded within normal limits to stimulation with an explorer. A panoramic radio2] graph was taken (Fig. 2), revealing the presence of radiopaque material (AH Plus) in the periapical area of tooth \#18 (universal) and spreading distally along the mandibular canal.

After discussing treatment options with the patient, it was decided to monitor the progress with periodic follow-up visits. The patient noticed a very rapid improvement during the first months after the incident. Seven months later, she showed significantly less paresthesia, and the anesthesia in the region of the lower left lip was decreased compared with the initial situation. However, there have been no significant improvements during the subsequent 3 years. The skin anesthesia on ] the left side of the lower lip persists (Fig. 3), and the radiopaque material in the periapical area of tooth \#37 is still radiographically evident

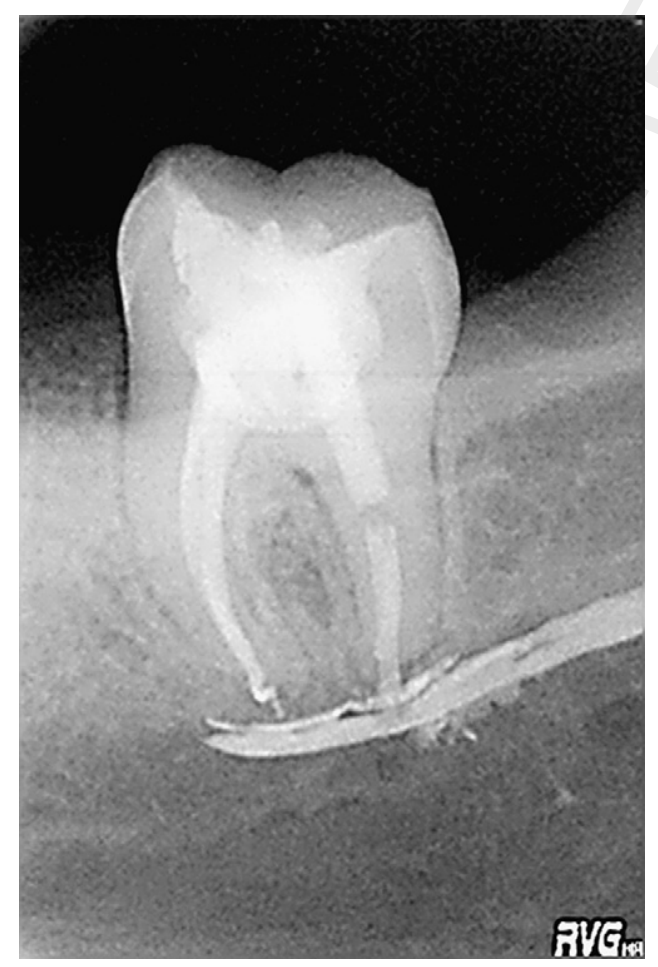

Figure 1. Post-treatment periapical radiograph. Presence of the extruded root canal sealer in the mandibular canal is evident.

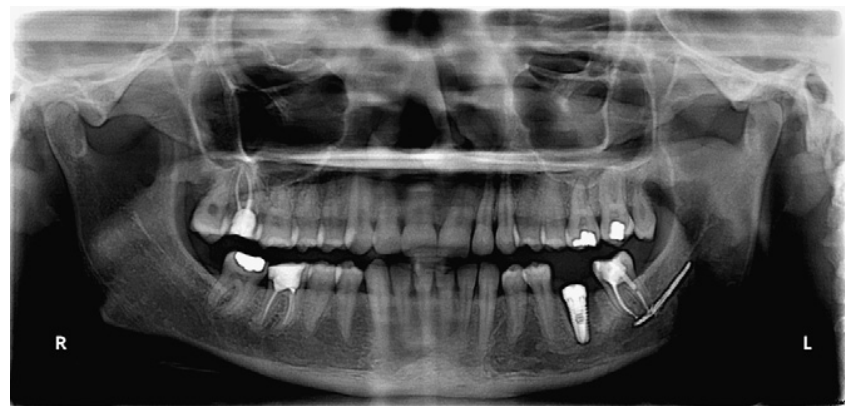

Figure 2. Panoramic radiograph taken the day after showing endodontic paste in the periapical zone of tooth \#37 and the inferior alveolar canal.

\section{Discussion}

Sensory loss or alteration in the territory of the inferior alveolar nerve, the chin region, and lower homolateral half of the lip is a relatively infrequent complication in daily dental practice and is normally the result of an inadequate dental treatment (12). One of the potential iatrogenic causes of this problem is the incorrect treatment of the root canals of a lower molar or premolar (overextension and/or overfilling). The proximity of the mandibular canal to the apices of the premolar and molar teeth requires a careful radiographic diagnosis when endodontic treatment of these teeth is planned. An initial pretreatment radiograph of the mandibular teeth will reveal the proximity of the canal to the apices (2). Preventive measures such as the use of an electronic apex detector, the application of a good apical stop, or moderate condensation will help avoid overfilling or overextending the endodontic material (11).

During endodontic treatment, it is extremely important to address the cleaning and shaping of the apical third accurately, knowing corrected length and width. The use of an electronic apex detector together with a radiograph taken with the files in position will not only ensure the correct working length but also prevent perforation of the canal and possible subsequent damage to the inferior alveolar nerve resulting from the endodontic treatment.

In the case reported here, preventive measures were taken. The root length was estimated by using an apex detector and confirmed with a periapical radiograph. Poor length control does not seem to be the obvious cause of the overextension of sealer in this case. Moreover, only a small quantity of sealer was introduced into the root canal by using a manual instrument. The main cone was placed covered with

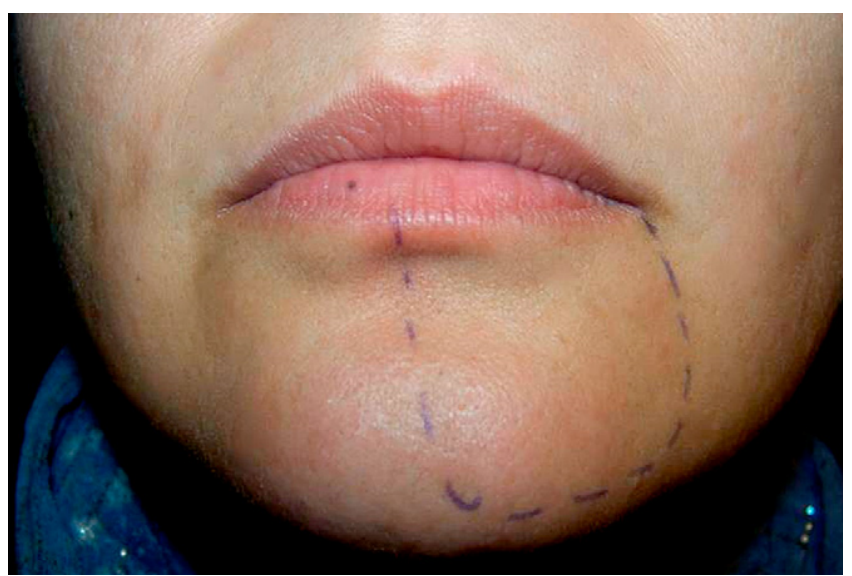

Figure 3. Area of mental nerve anesthesia after 3.5 years is outlined on the skin. 


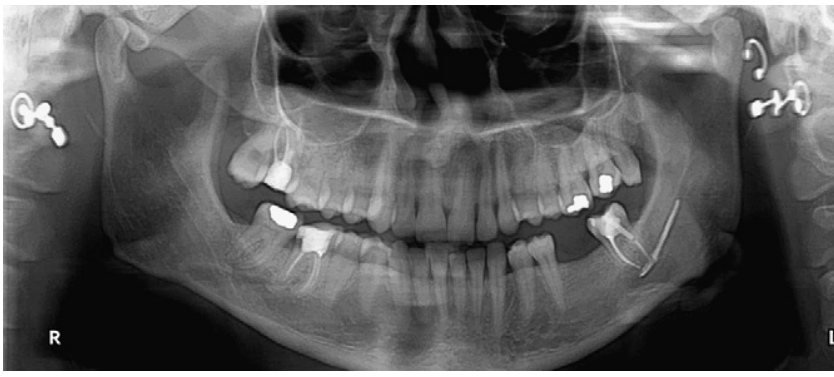

Figure 4. Panoramic radiograph taken 3.5 years after the accident showing the persistence of the endodontic paste in the periapical zone of tooth \#37 and the inferior alveolar canal.

a minimal quantity of sealer as well as each additional cone. Likewise, root does not seem to be significantly overfilled. However, the clinician did not use a master gutta-percha cone film before obturation.

Experimental studies have shown that eugenol and paraformaldehyde are the main materials causing neurotoxic reactions (3). The irrigation solutions, such as sodium hypochlorite and ethylenediaminetetraacetic acid (EDTA), might leak into the canal and damage the nerve chemically. Cytotoxic effects of EDTA (16), eugenol (17), and hypochlorite (18) have been described. Escoda-Francoli et al (19) suggested that some of the materials used in certain sealer cements, such as calcium tungstate (scheelite [CaW04]) and zirconium oxide (baddeleyite [ $\mathrm{ZrO2}]$ ), are not totally reabsorbable or innocuous and do not seem to be well-tolerated when overextended beyond the apical foramen.

AH Plus is one of the epoxy resin-based root canal sealers most commonly used. The monomer 2,2-bis[4-(2-hydroxy-3-methacrylyloxypropoxy)phenyl]-propane (BisGMA), prepared from bisphenol A and glycidyl methacrylate, is the major ingredient of the epoxy resinbased root canal sealers AH 26 and AH Plus (20). AH 26 cures with the generation of formaldehyde as a by-product, but AH Plus only releases small amounts of formaldehyde (21). However, AH Plus can cause cytotoxic effects (22) when extruded into the mandibular canal (4). Moreover, it has been shown that its component bisphenol A can cause cytotoxic effects (23).

Serper et al (24) investigated the neurotoxic effects of the root canal filling materials Endomethasone, N2 Universal, Traitement SPAD, Sealapex, and Calciobiotic Root Canal Sealer on isolated rat sciatic nerves after local application, demonstrating the neurotoxic effects of root canal filling materials. They observed that recovery from chemical insults to nerve structures was relatively slow and was incomplete in the in vitro conditions. A larger and more rapid and appreciable recovery was found with sealers without paraformaldehyde and eugenol, which seems to be less toxic to nervous structures when compared with other compounds containing these substances.

In the present case, the buccal gingival tissues over the left mandibular molar and premolar teeth felt no sensation. This could be explained because although the buccal nerve normally supplies these tissues, accessory branches of the inferior alveolar nerve have been described $(25,26)$.

A literature review of paresthesia and anesthesia cases attributable to the extrusion of a root canal sealer indicated that the surgical removal of the sealer from the mandibular canal is an effective treatment and might restore normal sensation in the affected region $(9,19)$. However, in the present case, the patient did not want surgical treatment, even though she exhibited complete lip skin anesthesia 3.5 years after the endodontic mishap. This case illustrates the need to expend great care with all endodontic techniques when performing nonsurgical root canal therapy, especially when the root apices are in close proximity to vital anatomic structures such as the inferior alveolar canal.

\section{References}

1. Koseoglu BG, Tanrikulu S, Sübay RK, Sencer S. Anesthesia following overfilling of a root canal sealer into the mandibular canal: a case report. Oral Surg Oral Med Oral Pathol Oral Radiol Endod 2006;101:803-6.

2. Poveda R, Bagán JV, Diaz Fernández JM, Sanchis JM. Mental nerve paresthesia associated with endodontic paste within the mandibular canal: report of a case. Oral Surg Oral Med Oral Pathol Oral Radiol Endod 2006;102:e46-9.

3. Morse DR. Infection-related mental and inferior alveolar nerve paresthesia: literature review and presentation of two cases. J Endod 1997;23:457-60.

4. Tamse A, Kaffe I, Littner MM. Paraesthesia following over extension of AH26: report of two cases and review of the literature. J Endod 1982;8:88-90.

5. Rowe AHR. Damage to the inferior dental nerve during or following endodontic treatment. Br Dent J 1983;153:306-7.

6. Brodin P, Røed A, Aars H, Ørstavik D. Neurotoxic effects of root filling materials on rat phrenic nerve in vitro. J Dent Res 1982;6:1020-3.

7. Gatot A, Tovi F. Prednisone treatment for injury and compression of inferior alveolar nerve: report of a case of anesthesia following endodontic treatment. Oral Surg Oral Med Oral Pathol Oral Radiol Endod 1986;62:704-6.

8. Kothary P, Cannell H. Bilateral mandibular nerve damage following root canal therapy. Br Dent J 1996;180:189-90.

9. Scolozzi P, Lombardi T, Jaques B. Successful inferior alveolar nerve decompression for dysesthesia following endodontic treatment: report of 4 cases treated by mandibular sagittal osteotomy. Oral Surg Oral Med Oral Pathol Oral Radiol Endod 2004;97: 625-31.

10. Kaufman AY, Rosenberg L. Paraesthesia caused by Endomethasone. J Endod 1980;6: 529-31.

11. Neaverth EJ. Disabling complications following inadvertent overextension of a root canal filling material. J Endod 1989;15:135-9.

12. Gallas-Torreira MM, Reboiras-López MD, García-García A, Gándara-Rey J. Mandibular nerve paresthesia caused by endodontic treatment. Med Oral 2003;8:299-303.

13. LaBlanc JP, Epker BN. Serious inferior alveolar nerve dyesthesia alter endodontic procedure: report of three cases. J Am Dent Assoc 1984;108:605-7.

14. Grotz KA, Al-Nawas B, de Aguiar EG, Schulz A, Wagner W. Treatment of injuries to the inferior alveolar nerve after endodontic procedures. Clin Oral Invest 1998;2:73-6.

15. ABE (American Board of Endodontics). Pulpal \& periapical diagnostic terminology. Available at: http://www.aae.org/NR/rdonlyres/0A9E773B-506D-4B63-884EDA68381CEAB0/0/ABETerminologyMay2007.doc. Accessed.

16. Segura JJ, Calvo JR, Guerrero JM, Jimenez-Planas A, Sampedro C. EDTA inhibits in vitro substrate adherence capacity of macrophages: endodontic implications. J Endod 1997;23:205-8.

17. Segura JJ, Jiménez-Rubio A. Effect of eugenol on macrophage adhesion in vitro to plastic surfaces. Endod Dent Traumatol 1998;14:72-4.

18. Jiménez Rubio A, Segura JJ, Jiménez A, Guerrero JM, Calvo JR. "In vitro" study of the effect of sodium hypochlorite and glutaraldehyde on substrate adherence capacity of macrophages. J Endod 1997;23:562-4.

19. Escoda-Francoli J, Canalda-Sahli C, Soler A, Figueiredo R, Gay-Escoda C. Inferior alveolar nerve damage because of overextended endodontic material: a problem of sealer cement biocompatibility? J Endod 2007;33:1484-9.

20. Peutzfeldt A. Resin composites in dentistry: the monomer systems. Eur J Oral Sci 1997;105:97-116.

21. Leonardo MR, Bezerra da Silva LA, Filho MT, Santana da Silva R. Release of formaldehyde by four endodontic sealers. Oral Surg Oral Med Oral Pathol Oral Radiol Endod 1999;88:221-5.

22. Pulgar R, Segura-Egea JJ, Fernández MF, Serna A, Olea N. The effect of AH 26 and AH Plus on MCF-7 breast cancer cells proliferation in vitro. Int Endod J 2002;35:551-6.

23. Segura-Egea JJ, Jiménez-Rubio A, Pulgar R, Olea N, Guerrero JM, Calvo JR. In vitro effect of the resin component bisphenol A on macrophage adhesion to plastic surfaces. J Endod 1999;25:341-4.

24. Serper A, Üçer 0, Onur R, Etikan I. Comparative neurototxic effects of root canal materials on rat sciatic nerve. J Endod 1998;24:592-4.

25. Carter RB, Keen EN. The intramandibular course of the inferior alveolar nerve. J Anat 1971;108:433-40.

26. Loizeaux AD, Devos BJ. Inferior alveolar nerve anomaly. J Hawaii Dent Assoc 1981; $12: 10-1$. 